\title{
Program Komputer Berbasis Matlab untuk Perhitungan Charge Occurence Probability Data Self Potensial
}

\author{
${ }^{1}$ Muhammad Zuhdi , ${ }^{2}$ Jannatin Ardhuha, ${ }^{3}$ Kosim, ${ }^{4}$ Wahyudi, ${ }^{5}$ Muhammad Taufik \\ $1,2,3,4,5$ Prodi Pendidikan Fisika, FMIPA, Universitas Mataram, Jln. Majapahit No 62, \\ Mataram, NTB, 83000 \\ Email Korespondensi: mzuhdi@unram.ac.id
}

\begin{tabular}{|c|c|}
\hline Arti & bstract \\
\hline $\begin{array}{l}\text { Received: October } 2020 \\
\text { Revised: December } 2020 \\
\text { Published: December } 2020\end{array}$ & \multirow{2}{*}{$\begin{array}{l}\text { Computer Program Based on Matlab for Calculating Charge Occurrence } \\
\text { Probability of Self Potential Data. Self Potential arises due to electric charge } \\
\text { of minerals in contact with the electrolyte solution around these minerals. } \\
\text { Charge Occurrence Probability (COP) is one of the methods of interpretation } \\
\text { of potential self data, the measurement of which is carried out using two } \\
\text { porouspot electrodes. This study aims to create a computer-based program } \\
\text { Matlab is for calculating COP. The stages of this research are creating } \\
\text { program algorithms, making Matlab-based syntax and making the main } \\
\text { program for COP calculation. The program that has been created is then } \\
\text { tested on synthetic data formed by the convolution of potential fields with } \\
\text { random numbers. The study is limited to two-dimensional computation } \\
\text { algorithms. Theoretically, the resulting resolution of this algorithm depends on } \\
\text { the data density of the self potential. This program is proven to provide a good } \\
\text { map for interpretation of potential self data. }\end{array}$} \\
\hline ncial, COP, Matlab & \\
\hline Infor & Abstrak \\
\hline Dipub & \multirow{2}{*}{$\begin{array}{l}\text { Self Potensial muncul karena adanya muatan listrik dari mineral yang } \\
\text { bersentuhan dengan larutan elektrolit di sekitar mineral ini. Charge Occurrence } \\
\text { Probability (COP) adalah salah satu metode interpretasi dari data self potensial } \\
\text { yang pengukurannya dilakukan dengan menggunakan dua elektroda porouspot. } \\
\text { Penelitian ini bertujuan untuk membuat program computer berbasis Matlab } \\
\text { untuk perhitungan COP. Tahapan penelitian ini adalah pembuatan algoritma } \\
\text { program, pembuatan sintax berbasis Matlab dan Pembuatan program utama } \\
\text { untuk perhitungan COP. Program yang telah dibuat kemudian diuji-coba pada } \\
\text { data sintetis yang dibentuk oleh konvolusi medan potensial dengan bilangan } \\
\text { random. Program komputer pada penelitian dibatasi untuk algoritma } \\
\text { perhitungan dua dimensi. Secara teoritis resolusi yang dihasilkan dari algoritma } \\
\text { ini tergantung pada kerapatan data potensialal diri. Program ini terbukti dapat } \\
\text { memberikan peta yang baik untuk interpretasi data self potensial. }\end{array}$} \\
\hline & \\
\hline
\end{tabular}

Sitasi: Zuhdi, M., Ardhuha, J., Kosim, K., Wahyudi, W., Taufik, M. (2020). Program Komputer Berbasis Matlab untuk Perhitungan Charge Occurence Probability Data Self Potensial. Kappa Journal. 4(2), 172-178

\section{PENDAHULUAN}

Spontaneous potensial (SP) atau juga sering disebut dengan self potensial adalah salah satu metode geofisika keliatrikan yang didasarkan pada sifat listrik material di dalam bumi. Metode self potensial digunakan untuk eksplorasi mineral terutama mineral yang memiliki sifat kelistrikan atau menghasilkan larutan elektrolit. Mineral yang dapat dieksplorasi dengan metode SP ini adalah oksida logam, sulfida dan beberapa mineral seperti magnetit dan pirit. Metode ini juga tepat digunakan untuk eksplorasi sumber panas bumi untuk meningkatkan ketersediaan sumber energi baru yang lebih ekonomis. 
Tegangan listrik yang terukur di permukaan adalah hasil dari polarisasi mineral yang di dalam bumi. Tegangan ini juga dapat dihasilkan oleh adanya aliran muatan listrik karena pergerakan zat cair dalam bumi. Potensial listrik ini juga dapat ditimbulkan oleh aktivitas makhluk hidup (bioelektrik) dan biokimia di dalam bumi. Biasanya terdapat perbedaan tegangan yang relatif besar dari tempat yang sedikit tumbuhannya dengan tempat yang vegetasinya padat.

Perbedaan potensial juga dapat ditimbulkan karena undulasi topografi. Semakin tinggi suatu tempat, maka potensial listrik di tempat itu cendrung semakin negatif. Potensial listrik yang terukur dipermukaan juga dapat timbul karena perbedaan $\mathrm{PH}$ atau tingkat keasaman dari material tanah di atas water table dengan tingkat keasaman dibawah water table. Perbedaan ini muncul karena adanya tubuh batuan yang terendam sebagian di bawah water table dan bagian lainnya di atas water tabel. Charge Occurrence Probability adalah salah satu cara untuk interpretasi data Self Potensial, untuk itu perlu dibuat Program berbasis Matlab untuk perhitungan COP.

Tujuan dari penelitian ini adalah untuk mengembangkan perangkat lunak untuk perhitungan COP sebagai cara terbaik untuk melakukan pemodelan bawah permukaan sebagai alat interpretasi data Self Potensial. Produk akhirnya berupa paket program perhitungan COP dengan manfaat khusus untuk pemodelan bawah permukaan. Software perhitungan $\mathrm{COP}$ berbasis MATLAB ini diharapkan mampu menjadi alat interpretasi yang dapat menambah dan melengkapi informasi struktur bawah permukaan yang berkaitan dengan COP data self potensial.

Revil dkk. 2003 mengaplikasikan metode SP menggunakan prinsip elektrografi untuk menyelidiki sumber-sumber elektromagnetik yang terapkan pada hidrogeologi. Febriani dan Daniati, 2017, menginterpretasi persebaran mineral pasir besi melalui metode SP ini. Willen dkk. 2013 melakukan pemodelan patahan dengan prinsip simulated annealing menggunakan metode SP. Metode SP juga dapat dilakukan untuk membuat peta zona korosi pipa terpendam yang didasarkan pada potensial alami (Amalia 2017). Basid dkk. 2014 memetakan daerah potensi geothermal menggunakan metode SP. Hal ini dapat dilakukan karena aktivitas panas bumi selalu berhubungan dengan aktivitas giokimia yang menghasilkan larutan elektrolit. Indriana dkk. 2007 melakukan interpretasi lumpur purba Bledug Kuwu di Kabupaten Grobogan, Propinsi Jawa Tengah. Jouniaux dkk. 2009 menggunakan metode SP untuk eksplorasi hidrogeologi. Tomografi geolistrik pada daerah rawan longsor di Giarossa, Italia Selatan dilakukan oleh Lapenna dkk. (2003). Maurielo dan Patella (1999) juga menggunakan tomografi dengan metode geolistrik. Patella 1997 menerapkan metode ini untuk tomografi secara global termasuk pengaruh efek topografi dan perhitungan yang teliti. Penggunaan metode SP untuk interpretasi bawah permukaan di Farco d'Izzo earthflow di Italia bagian selatan dilakukan oleh Perronea dkk. 2004.

Pengukuran SP dilakukan di atas permukaan bumi dengan menggunakan elektroda tembaga yang direndam dalam dalam wadah gerabah yang berisi larutan kupri sulfat atau terusi yang rumus kimianya $\mathrm{CuSO}_{4}$. Larutan perusi dan elektroda tembaga diletakkan di dalam wadah yang terbuat dari gerabah berukuran sekitar 1 hingga 1,5 liter. Gerabah yang digunakan harus berpori, sehingga elektroda ini sering disebut dengan porouspot. Kedua elektroda dipisahkan satu sama lain untuk mendapatkan beda potensial di berbagai titik di atas permukaan.

Perlu dipahami bahwa beda potensial yang terukur adalah hasil dari pengukuran dengan menggunakan voltmeter yang dicatat polaritasnya. Voltmeter yang digunakan pada pengukuran SP harus menggunakan voltmeter dengan kualitas dan ketelitian tinggi dengan nilai hambatan dalam Voltmeter yang nilainya sangat besar. Untuk melakukan proses pengukuran dengan cepat, sebaiknya menggunakan voltmeter jenis digital, karena Voltmeter jenis ini tidak memerlukan ketelitian paralaks dalam pembacaanya. 
Hasil pengukuran data potensial di permukaan ini kemudian dipetakan dalam bentuk peta potensial yang terdiri dari garis-garis kontur isopotensial. Berdasarkan nilai tegangan yang diambil dari peta iso potensial ini, COP dapat dihitung dan dipetakan. Penggunaan Matlab untuk perhitungan COP, sejauh penelusuran penulis belum di temukan dalam beberapa riset sebelumnya. Perhitungan COP menggunakan Matlab ini merupakan kebaruan dari riset yang dilakukan.

\section{METODE}

Penelitian ini dilakukan melalui beberapa tahap. Tahap pertama adalah pembuatan pembuatan algoritma perhitungan COP. Tahap berikutnya adalah penulisan syntax berbasis Matlab dari tiap-tiap Langkah program, kemudian dilanjutkan dengan penggabungan sintak dan menjadi program utama perhitungan COP berbasis Matlab. Program yang telah dibuat kemudian diuji-coba pada data sintetis. Hasil perhitungan ini ditampilkan dalam bentuk peta COP yang akan memudahkan interpretasi data self potensial. Semua tahapan penelitian dilakukan di Labotarium Fisika, FKIP, Universitas Mataram. Peralatan yang digunakan dalam pembuatan program berbasis Matlab ini adalah personal computer dengan spesifikasi minimum Processor Core 2 Duo ${ }^{\circledR} 2.7 \mathrm{GHz}$, memory (Ram) $8 \mathrm{~GB}$, hard disk $1 \mathrm{~TB}$, dan VGA card $512 \mathrm{MB}$.

Peta COP dapat dihitung berdasarkan sebaran nilai potensial pada suatu garis lurus di atas permukaan bumi. Perhitungan ini dilakukan pada sebuah garis potensial tersebut yang diinterpretasi ke dalam nilai COP dalam peta penampang vertical 2 dimensi. Resolusi dari peta Charge Occurrence Probability (COP) tergantung pada jumlah dan kerapatan data. Semakin kecil jarak antar elektroda pada saat pengukuran beda potensial, maka semakin banyak data yang dihasilkan sehingga menghasilkan peta COP beresolusi tinggi. Semakin renggang titik pengambilan data, maka resolusinya semakin rendah. Untuk merubah peta potensial dipermukaan menjadi peta potensial dalam bentuk garis di permukaan dapat dilakukan melalui gridding kemudian mencuplik suatu garis dari hasil gridding. Tiap-tiap garis potensial ini kemudian dihitung Charge Occurrence Probabilitynya (COP) dengan program berbasis Matlab yang telah dibuat.

Kedalaman target sumber pada perhitungan Charge Occurrence Probability (COP) ditentukan dengan panjangnya lintasan horizontal yang dihasilkan. Semakin panjang lintasan potensialnya maka kedalaman target juga semakin besar. Jarak grid kedalaman peta Charge Occurrence Probability (COP) dibuat sama dengan jarak grid horizontal pada peta self potensial. Anomali data self potensial pada suatu garis yang berada di sumbu $\chi$ dinyatakan dengan notasi $\Delta \mathrm{V}(\chi)$, maka pada sebuah titik dengan posisi $\xi$ yang berada di garis $\chi$ di kedalaman $\delta$, nilai COP sebagai fungsi posisi dan kedalaman dapat dinyatakan dengan $\eta(\xi, \delta)$ dirumuskan oleh Patella 1997, sebagai:

$$
\eta(\xi, \delta)=-\mathrm{D} \delta \Sigma \mathrm{x} \Delta \mathrm{V}(\chi)(\chi-\xi)[(\chi-\xi) 2+\delta 2]^{-3 / 2}
$$

dengan

$$
\mathrm{D}=2.21 / 2[\pi \Sigma \mathrm{x} \Delta \mathrm{V} 2(\chi)]^{-1 / 2}
$$

Untuk data self potensial berupa garis akan didapatkan peta COP 2 dimensi. Bentangan adalah panjang garis lurus dari data survei self potensial. Grid Space adalah jarak antar titik pengukuran terhadap titik pengukuran selanjutnya. Grid point adalah jumlah titik pencuplikan data dalam sebuah bentangan. Jumlah grid point adalah hasil bagi nilai panjang bentangan dengan nilai grid space. Resolusi dari peta COP tergantung pada nilai bentangan, grid space, grid point dan grid depth (Zuhdi, dkk 2019). 


\section{HASIL DAN PEMBAHASAN}

Hasil perhitungan dengan program ini memiliki resolusi yang besarnya tergantung dari jumlah grid point dan kedalaman target. Jumlah grid point di tentukan oleh Panjang garis survey di permukaan sedangkan kedalaman grid ditentukan saat mengentry pada dialog program.

Dalam survey geofisika, secara umum kedalaman maksimum dari target yang dapat dicover oleh survey sebesar 1/3 dari panjang garis survey. Jika target yang akan dicover memiliki kedalaman $1 \mathrm{~km}$, maka panjang garis survey minimalnya adalah $3 \mathrm{~km}$. Program ini di buat dengan dialog program yang kedalamannya tidak terbatas, namun pemakai program disarankan untuk memasukkan kedalaman maksimum sebesar 1/3 dari panjang garis survey.

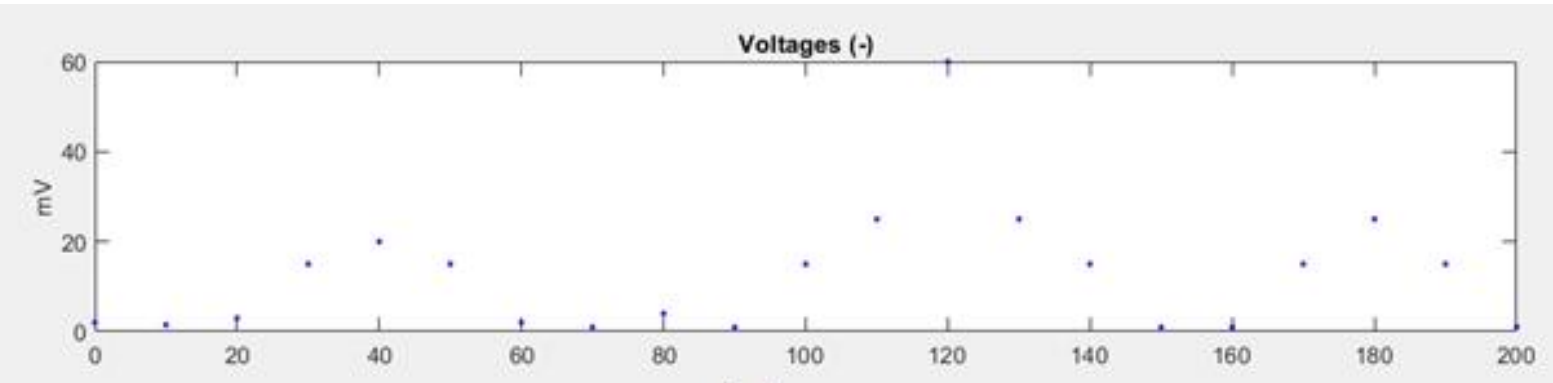

(a)

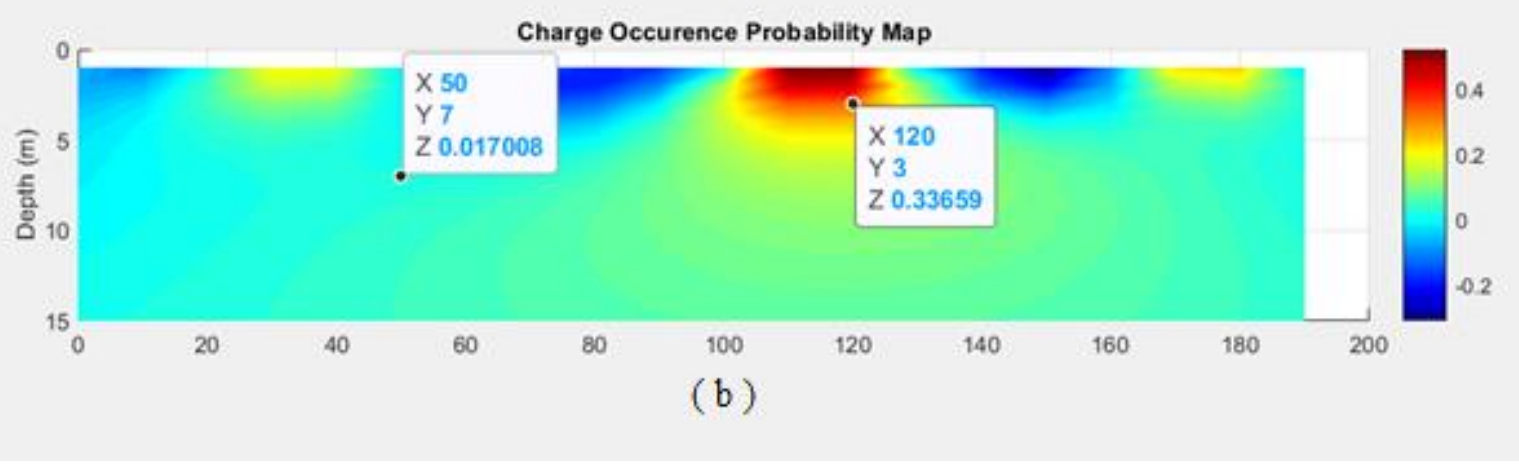

Gambar 1. Potensial daerah survey dan peta COPnya

Gambar 1 (a) menunjukkan nilai potensial pada garis survey dengan satuan milli Volt pada sumbu vertikalnya dan posisi titik pengukuran pada sumbu horizontal. Gambar 1 (b) adalah peta COP yang merupakan hasil perhitungan dari program computer yang telah dibuat. Pengguna program ini dapat mengetahui nilai COP di sembarang titik pada peta dengan mengklik cursor pada titik tersebut. Pada tip point tersebut, huruf $\mathrm{X}$ adalah posisi pada garis horizontal, $\mathrm{Y}$ adalah kedalaman dan $\mathrm{Z}$ adalah nilai COPnya. 


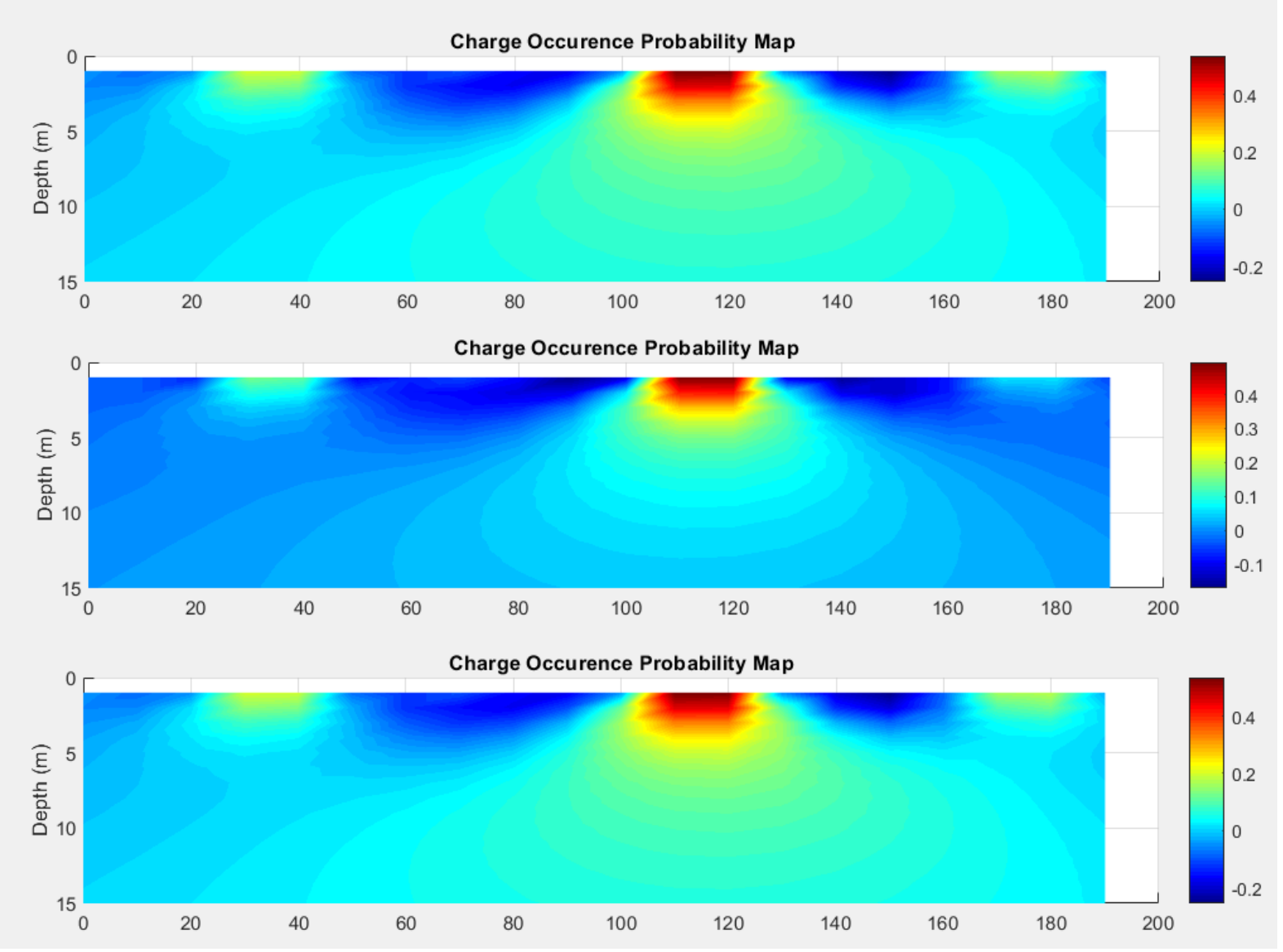

Gambar 2. Gabungan 3 peta 2 dimensi untuk interpretasi 3 dimensi

Gambar 2 adalah 3 buah gambar yang merupakan paduan dari 3 garis survey yang memiliki arah sejajar. Data ketiga garis tersebut adalah data sintetis yang merupakan hasil konvolusi antara bilangan random terhadap medan potensial oleh muatan titik. Penggabungan tersebut dapat memberikan interpretasi terpisah secara 2 dimensi dan jika digabungkan dapat menjadi alat interpretasi 3 dimensi. Resolusi dari peta COP tergantung pada nilai bentangan, grid space, grid point dan grid depth. Semakin besar bentangan data self potensial maka resolusi akan semakin besar pula, sedangkan semakin besar grid space maka resolusi akan semakin kecil.

\section{KESIMPULAN}

Program untuk penghitungan COP akan mudah jika dilakukan dalam bentuk operasi matriks sehingga dapat dilakukan dengan mudah melalui program berbasis Matlab. Perhitungan COP ini dilakukan secara deskrit dan nilainya tidak kontinyu, sehingga mudah diolah secara digital. Perhitungan COP mudah dilakukan secara digital dengan melakukan gridding data self potensial baik dua dimensi maupun tiga dimensi. Semakin besar bentangan data self potensial maka resolusi akan semakin besar pula, sedangkan semakin besar grid space maka resolusi akan semakin kecil.

\section{UCAPAN TERIMAKASIH}

Ucapan terimakasih kami sampaikan kepada LPPM Universitas Mataram yang telah membiayai penelitian ini. Ucapan terimakasih juga kami sampaikan kepada Bapak Syamsuddin, Rahadi Wirawan dan Bakti Sukrisna di FMIPA Universitas Mataram atas diskusi matematis dan geofisis untuk penyusunan artikel ini. Jazaakumullahu khoiron katsiiron. 


\section{DAFTAR PUSTAKA}

Amalia, M. (2017), Pemetaan Lingkungan Korosi Bawah Permukaan Menggunakan Metode Self Potential Bedasarkan Native Potential Pada Daerah Unit 7 Dan 8 Pt. Ipmomi, Skripsi, ITS.

Basid, A., Andrini, N., Arfiyaningsih, S. (2014), Pendugaan Reservoir Sistem Panas Bumi Dengan Menggunakan Survey Geolistrik, Resistivitas Dan Self Potensial (Studi Kasus: Daerah Manifestasi Panas Bumi di Desa Lombang, Kecamatan Batang-Batang, Sumenep), Jurnal Neutrino Vol. 7, No. 1 Oktober 2014

Indriana, R. D., Nurwidyanto, M.I., Haryono, K.W. (2007), Interpretasi Bawah Permukaan Dengan Metode Self Potential Daerah Bledug Kuwu Kradenan Grobogan, Berkala Fisika, ISSN: 1410 - 9662 Vol 10, No.3, Juli 2007 hal. 155-167.

Jouniaux, L., Maineult, A., Naudet, V., Pessel, M. Sailhac, P. (2009). Review of selfpotential methods in hydrogeophysics, C. R. Geoscience 341 (2009) 928-936.

Lapenna, V., Lorenzo, P., Perrone, A., Piscitelli, S., Sdao, F., Rizzo, E. (2003). Highresolution geoelectrical tomographies in the study of Giarrossa landslide (southern Italy). Bull Eng Geol Env (2003) 62:259-268.

Mauriello, P., and Patella, D., (1999), Resistivity anomaly imaging by probability tomography, Geophysical Prospecting, 47, 411-429

Patella, D. (1997), Introduction to Ground Surface Self Potential Tomography. Geophysical Prospecting, 45, 653-681.

Patella, D. (1997), Self Potential Global Tomography Including Topographic Effect. Geophysical Prospecting, 45, 843-863.

Perronea, A., Iannuzzia, A., Lapennaa, V. Lorenzob, Piscitellia, S., Rizzoa, E., Sdao F. (2004), High-resolution electrical imaging of the Varco d'Izzo earthflow (southern Italy), Journal of Applied Geophysics 56 (2004) 17- 29.

Revil, A., Naudet, V., Nouzaret, J., Pessel, M., (2003), Principles of electrography applied to self-potential electrokinetic sources and hydrogeological applications. Water Resources Research, Vol. 39, No. 5, 1114

Febriani, S.D.A., Daniyati, R., (2017), Interpretasi Persebaran Mineral Pasir Besi Menggunakan Metode SP (Self Potential) di Desa Kepanjen, Seminar Nasional Hasil Penelitian 2017, ISBN: 978-602-14917-5-1

Wilen, Arman, Y., Putra, Y.S., (2013), Pemodelan Zona Patahan Berdasarkan Anomali Self Potensial (SP) Menggunakan Metode Simulated Annealing. PRISMA FISIKA, Vol. I, No. 3 (2013), Hal. 103- 109.

Zuhdi, M, Syamsuddin, Sukrisna, B. (2019), Algoritma Perhitungan Charge Occurrence Probability (COP) Pada Data Self Potensial. Jurnal Penelitian dan Pembelajaran Fisika Indonesia (JPPFI), Vol 1, no 1. Hal: 1-4. 